\title{
Qual pode ser o alcance de uma metáfora?
}

\author{
What may be the scope of a metaphor? \\ Cristina Martins Fargetti ${ }^{1}$
}

\begin{abstract}
Resumo
Este artigo trata, à luz da Teoria da Metáfora Conceptual, defendida por Lakoff e Johnson (2002), duas questões cruciais para aqueles que se dedicam à interpretação e tradução de outras línguas e culturas: a) se as metáforas realmente existem e nos apercebemos delas como tais, como compreendemos realmente as metáforas provenientes de cultura/língua diferentes das nossas? e b) em que medida estamos autorizados, como pesquisadores, a estender uma metáfora, feita em outra cultura/língua, para a compreensão de sistemas complexos de pensamento?
\end{abstract}

Palavras-chave: Metáfora. Sistemas complexos de pensamentos. Línguas Indígenas.

\begin{abstract}
In the light of the Conceptual Metaphori Theory (Lakoff e Johnson (2002), this article deals with two crucial questions for those dedicated to the study of languages and cultures: a) if metaphors do exist, and we perceive them as such, how we really understand metaphors from other languages/cultures?, and b) In what extent we are authorized, as researchers, to extend a metaphor from other language/culture, aiming the comprehension of complex systems of thought?
\end{abstract}

Keywords: Metaphor. Complex systems of thought. Indigenous languages.

Estamos cercados por metáforas, e, por vezes, não nos damos conta da existência delas. Por exemplo, um maestro, em um ensaio, pode solicitar à orquestra que repita um trecho de uma música, a partir 'da cabeça' de um compasso determinado. ${ }^{2}$ Com isso, ele está, na verdade, pedindo que os músicos toquem a partir do início do compasso, de seu primeiro tempo. Isso

\footnotetext{
${ }^{1}$ UNESP - Faculdade de Ciências e Letras - Araraquara - Departamento de Linguística, Grupo LINBRA - CNPq - cmfarget@gmail.com. Agradeço ao CNPq o apoio financeiro, para trabalho de campo, pelo projeto de Edital Universal, processo 477669/2013-1 - "Uma proposta de obra lexicográfica para os juruna/yudjá do Xingu".

2 A expressão vem do italiano 'da capo', que quer dizer 'do início', embora 'capo' seja também 'cabeça'. Ao usar 'da cabeça' do compasso, o maestro traduz para o português, revelando a metáfora implícita. Também se usa 'da capo', em italiano mesmo, sem se mencionar algum trecho específico, para que os músicos repitam a peça musical a partir de seu começo, podendo ele ser o começo de um movimento de uma sinfonia, ou o começo do primeiro movimento da sinfonia, por exemplo.
} 
para um músico é tão óbvio, que não se atenta para o fato de ser na verdade uma metáfora. E assim muitas metáforas nos rodeiam, sem que nos apercebamos de sua existência, sem que nos demos conta desse uso diferenciado da língua.

O uso de metáfora na Ciência é comum em hipóteses, para fazer descobertas e interpretá-las, comunicá-las, debatê-las, como nos aponta Sardinha (2007). As metáforas então usadas podem abonar uma teoria, ou, com o passar do tempo, desaboná-la. A Terra vista como uma forma plana, circular, como uma mesa, foi uma metáfora do passado medieval, na Europa, para uma teoria que ficou então ultrapassada, ao se comprovar que a Terra é redonda. Vários pensadores morreram (ou quase!), por defenderem ideias diferentes das postuladas pela Igreja da época. Uma metáfora ou uma questão teológica? Mas, diga-se de passagem, a Terra ainda é pensada como plana em certas culturas, como a juruna, que a interpreta da seguinte forma: um grande quadrilátero, com dois grandes sapos em duas de suas arestas opostas, os quais seguram com suas cabeças o céu, que também é sustentado por uma árvore, amarrada nele com embira. Que o céu nunca caia sobre nossas cabeças, literalmente, é o que desejam os juruna.

Esta maneira de compreender a forma da Terra seria uma metáfora juruna? Provavelmente não. E então ficamos sempre no impasse de procurar saber os limites do que pode ser considerado metafórico. Explicação cosmogônica para os mais velhos da comunidade, e portanto para eles linguagem literal, porém linguagem metafórica para os mais jovens? Mas talvez para os europeus, com sua Terra-mesa, isso também tenha sido assim: o real e literal para uns, o metafórico para outros (e o irreal para alguns). Se as metáforas realmente existem e nos apercebemos delas como tais, como compreendemos realmente as metáforas provenientes de cultura/língua diferentes das nossas? Além disso, em que medida estamos autorizados, como pesquisadores, a estender uma metáfora, feita em outra cultura/língua, para a compreensão de sistemas complexos de pensamento?

\section{Pressupostos teóricos}

Como aponta Sardinha (2007), não é possível fazer um apanhado geral de todas as teorias sobre metáfora já elaboradas, uma vez que o assunto tem sido discutido há milhares de anos, tendo pontos de vista tradicionais, que a veem apenas como recurso estilístico, e também mais atuais, estando na base de certas teorias linguísticas, como a teoria sistêmico-funcional, de Halliday. Resta-nos um comprometimento com alguma vertente teórica, com cujos pressupostos concordemos.

Neste breve texto, adoto a teoria da metáfora conceptual, defendida por Lakoff e Johnson (2002), e a partir dela, utilizo certos conceitos, que passo a apresentar. A metáfora conceptual conceitua, por convenção, um domínio de experiência por meio de outro; é grafada com letras maiúsculas; ela se 
manifesta por expressões metafóricas a ela relacionadas. O domínio é a área de conhecimento relacionada à metáfora; os mapeamentos são relações feitas entre domínios e eles podem ser lícitos ou ilícitos; e os desdobramentos são as inferências que se pode fazer de uma metáfora. Nesta teoria, sobressai a ideia de que as metáforas são culturais, fazendo sentido dentro das sociedades em que ocorrem, não havendo, portanto, verdades absolutas. Para uma exemplificação disso, veja-se a seguir a análise que apresento.

Moura (2007) distingue, nas tendências mais recentes, as teorias da metáfora como ocorrência (tokens) das teorias da metáfora como tipo (types), assumindo esta última posição em sua análise de três verbos em uso metafórico ( explodir, arquivar, congelar). As primeiras teorias veriam as metáforas apenas em seus contextos, que então as explicariam. As teorias de tipo entenderiam como possíveis as generalizações a partir do uso. Assim, ele define que:

[...] a) o uso de metáforas explora a estrutura léxico-conceptual da linguagem; b) o uso de metáforas é sistemático, ou seja, existem tipos de metáforas, com relações paradigmáticas e sintagmáticas bem definidas, que guiam a interpretação de metáforas específicas. (Moura 2007: 431)

Isso aponta para uma relação entre linguagem e pensamento, que o autor descreve como:

A metáfora explora a rede conceptual da linguagem humana, que é altamente estruturada e sistemática. Isso não significa absolutamente que a linguagem não tem valor cognitivo ou que não seja um instrumento do pensamento. Ao contrário, ela é um instrumento justamente por justapor categorias semânticas que estão distantes na rede conceptual. Sem a metáfora, a mente humana perderia um excelente meio de navegar na rede conceptual da linguagem. Mas sem essa rede conceptual prévia estruturada, a metáfora perderia boa parte de sua eficácia. (Moura 2007: 448)

Com isso, ele deixa claro que a metáfora é um instrumento do pensamento, mas não existiria sem uma estrutura linguística, que lhe permite interpretações e sempre novos usos. Ela não é apenas cognitiva, como querem alguns, mas com forte determinação linguística, o que sua análise busca mostrar.

Moura (2012) distingue a metáfora da comparação, com relação à criação ou não de categorias. A comparação trabalha apenas com categorias já préexistentes; por exemplo, posso apresentar a comparação de um violão a uma viola, ambos pertencentes à categoria dos instrumentos de corda, sem arco. Já a metáfora cria categorias de coisas distintas; por exemplo, posso apresentar a metáfora 'a moça é um violão', em que 'moça' é o tópico, 'violão' é o veículo da metáfora, e a categoria criada refere-se à forma sinuosa do corpo, que não é pré-existente. 
Sobre a questão da verdade, Moura (2012) afirma que toda metáfora traz em si uma mentira. Como ele também cita, como outros autores, quando Romeu, personagem shakespeariana, diz "Julieta é o Sol", isso é falso, obviamente, pois uma pessoa não pode ser o astro Sol. Mas o que isso pode significar é mais poético do que uma expressão literal sobre a beleza de Julieta. Afinal, a linguagem serve não apenas para transmitir informações, mas também para expressar o belo. Nesse sentido, ele diz:

A metáfora é uma figura de linguagem que se assemelha à arte, na medida em que impõe um grau de libertação do real e do verdadeiro. Mas a metáfora não abandona totalmente o desejo de informar algo que possa ser considerado verdadeiro. Pode parecer complicado, mas metáfora cria uma mentira, para exprimir algo verdadeiro. Por exemplo, se um cientista afirma que o genoma é um livro, ele sabe que, estritamente falando, trata-se de uma mentira, pois o genoma não é, literalmente, um livro. No entanto, muitas vezes, a metáfora é a melhor maneira de exprimir algo, pois sem essa junção de contrários (genoma, livro), não conseguiríamos pensar com clareza sobre o assunto. Ou seja, a metáfora pode ser verdadeira, do ponto de vista de nosso pensamento. (Moura 2012: 116)

Não há como discordar do autor e penso que o que a obra de arte traz é a representação do belo, que varia de escola para escola, de cultura para cultura, de época para época, e o belo se faz representar pelo metafórico. Como direi mais à frente, o belo também deveria estar em nossas práticas acadêmicas como cientistas, ao buscarmos, além da clareza e concisão em nossas análises, também a elegância, o bom gosto, que estão intimamente ligados com a nossa relação com nossos leitores, estes não apenas acadêmicos.

\section{Os juruna do Xingu e o sistema de parentesco}

O povo juruna teve um expressivo crescimento populacional, a partir da década de 1960, quando contavam pouco mais de 40 pessoas, uma vez que hoje a população é estimada em torno de 500 pessoas, moradoras do Parque Indígena Xingu, MT. A língua da etnia é a juruna, da família juruna, tronco tupí (Rodrigues 1986). Os primeiros estudos linguísticos ocorreram a partir de 1989, em projeto de documentação e descrição, de que resultaram dissertação e tese (Fargetti 1992, 2007), e posteriormente, diversos estudos, inclusive com a formação de novos pesquisadores.

Estudos antropológicos foram realizados por Adélia Engrácia de Oliveira, no final da década de 1960, e por Tânia Stolze Lima, a partir da década de 1980. Estes estudos têm orientações diferentes, mesmo abordando assuntos semelhantes. A tese de Lima (1995) deu origem a uma nova visão sobre a 
relação humano-animal, com a teoria do Perspectivismo de Eduardo Viveiros de Castro (1996).

Há estudos das referidas autoras a respeito do sistema de parentesco do povo juruna (Lima 1995; Oliveira 1970), contudo, ambos não são coincidentes em seus resultados, e apresentam inconsistências de diferente tipo, o que demanda recoleta e reanálise. Para isso, há que se estudar a bibliografia sobre o assunto, vasta e diversificada, por seus primeiros estudos remontarem há praticamente 200 anos. Segundo Lèvi-Strauss (2003 [1967]), a proibição do incesto é tipicamente humana, contudo, muito relativa, pois o que é considerado incesto depende de cultura a cultura. Essa proibição está na base dos sistemas de parentesco, que diferem em cada povo. Em estudos linguísticos de línguas indígenas, por vezes, a complexidade do sistema de parentesco do povo não é mostrada, ficando-se com muitas dúvidas sobre o uso dos termos apresentados. Outra dificuldade é que, em sociedades pequenas, o grau de proximidade entre as pessoas é muito grande, por isso, para uma mulher, por exemplo, um mesmo homem pode ser seu cunhado, seu primo e seu marido, o que redunda em termos por vezes diferentes do parentesco que o pesquisador tem em mente (pensa que a falante disse "primo", mas disse "cunhado"). Vários antropólogos usam um sistema de abreviação em inglês para as descrições de cada termo. Ex: MB - "mother's brother" - "irmão da mãe" (nem sempre o termo empregado corresponde ao que chamamos de "tio", pois pode se estender a F- father "pai"). O sistema de parentesco juruna é classificado como dravidiano (relação estrutural com o sistema dravidiano da Índia do Sul), observado largamente na Amazônia, segundo Lima (1995). Seus traços típicos são a existência de casamentos preferenciais entre primos cruzados e dicotomia entre consanguinidade e afinidade (Lima, op.cit.). Apresenta distinção entre termos de referência e vocativos. Contudo, por vezes vocativos podem ser usados como referência, como pude observar. Por exemplo, upá "meu pai", bába "pai, vocativo", upá wï “meu pai chegou”, bába, wï áne? "pai, você chegou?", bába wï "meu pai chegou". Os termos de parentesco referenciais, em geral, são inalienáveis, com marcação de pessoa obrigatória, como observei em meu estudo. Em Fargetti (2015) abordo questões do fazer lexicográfico referentes aos termos de parentesco.

\section{O metafórico para o sistema de parentesco}

$\mathrm{Na}$ imagem-metáfora ocidental da árvore, para as genealogias, em geral, os ancestrais encontram-se na base da árvore, ficando os descendentes nos ramos e galhos superiores (mas há desenhos de árvores genealógicas em que se inverte essa posição, ficando ego na base da árvore, e seus ancestrais em seus galhos). Portanto, para o ocidente, a imagem-metáfora para o sistema de parentesco é muito recorrente, com variações, mas sempre em referência à árvore. Fala-se, 
por exemplo, na 'árvore genealógica de uma pessoa'. Contudo, essa imagemmetáfora não é universal.

Ao mencionar a concepção do sistema de parentesco, Lima (op.cit.) diz:

A compreensão que formamos do parentesco a partir de uma analogia com a árvore é estranha ao pensamento juruna, que o concebe segundo o modelo do batateiral. O modelo do batateiral atribui ao avô o papel de batata matriz ou inã 'ã da prole (assim como se diz que Senã'ã é o inã 'ã da humanidade); ele supõe a existência de múltiplos inã' $\tilde{a}$, e permite, por outro lado, projetar as relações de parentesco num espaço concêntrico onde o dentro e o fora se acham a um só tempo distinguidos e unidos por múltiplas relações. (Lima 1995: 320-321)

Assim, por essa concepção, o avô seria o tubérculo que dá origem aos outros descendentes, utilizando-se as raízes e batatas como sistema de parentesco, numa imagem invertida, pensando-se na árvore, com o antepassado (tubérculo mãe, para a botânica) em posição superior, mas embaixo da terra, e do qual se originariam os descendentes, em posição inferior ou lateral, como se vê na imagem a seguir.

\section{Figura 1 - ilustração de batateiral para a imagem-metáfora referida}

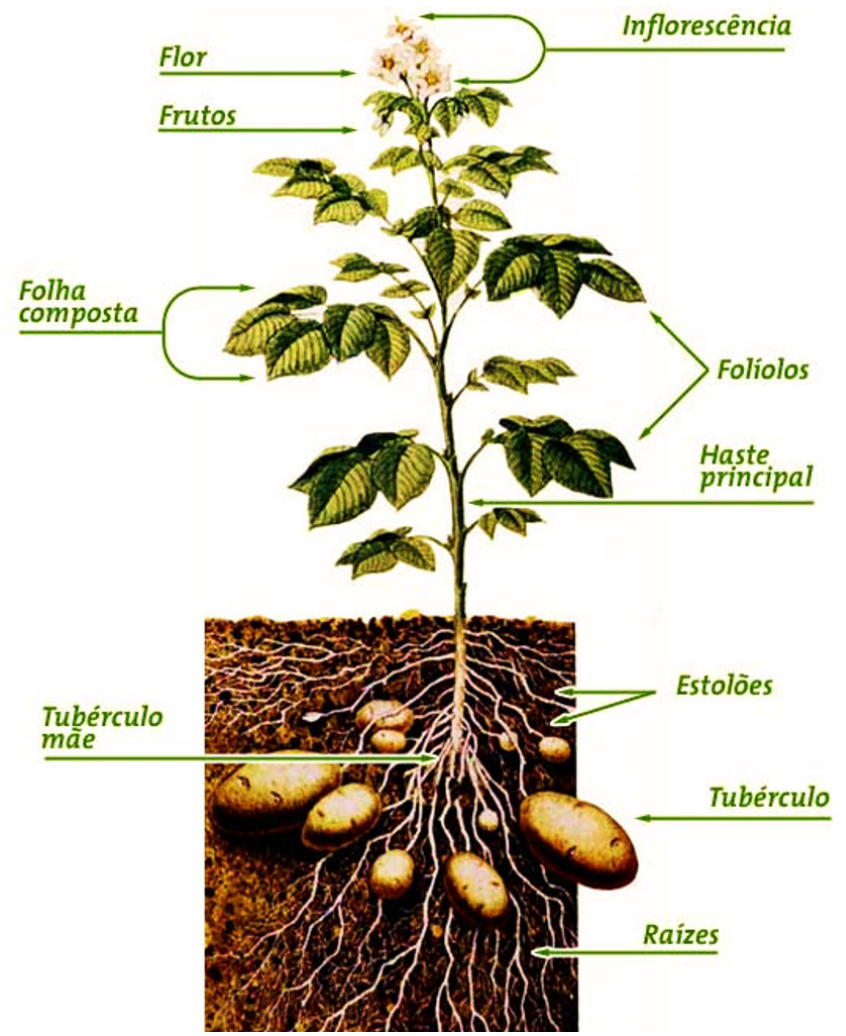

Fonte: Reifschneider (1987). 
Abaixo, observa-se a imagem-metáfora usada no site da ONG ISA, para o tronco tupí, em que as duas metáforas se unem: a árvore e o batateiral, uma vez que os descendentes aparecem como suas raízes.

\section{Figura 2 - Imagem-metáfora do tronco tupí}

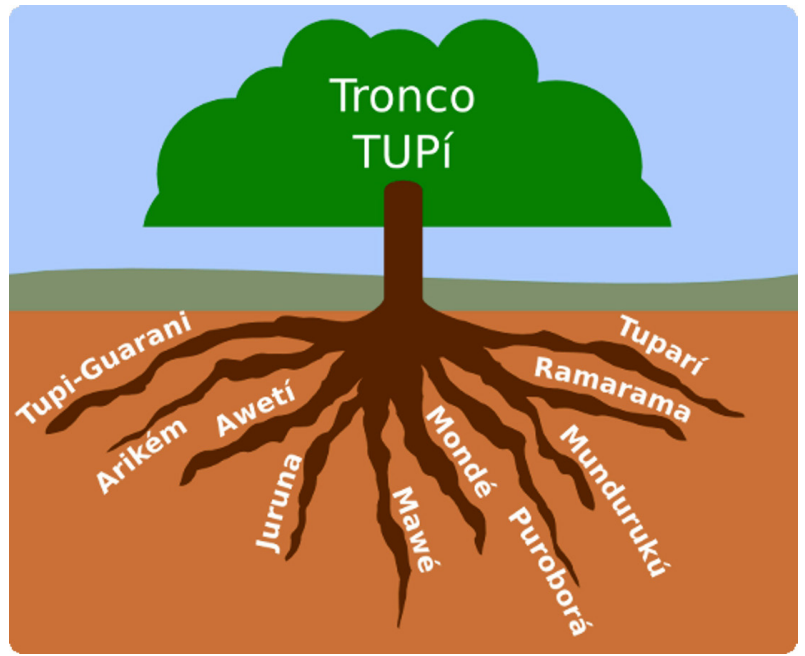

Fonte: http://pibmirim.socioambiental.org/linguas-indigenas

Através da metáfora criada a partir do nome do herói mítico, Sela'ã, Lima (1995) explica o sistema de parentesco. Ela parece reconhecer que os juruna dizem "nossa batata", no sentido de que se explicam como originários de Sela'ã, a batata de que se esparramaram. Ela percebe isso como metáfora para eles, pois sabe que Sela'ã, como primeiro homem e deus, soprou suas pegadas, das quais surgiram os homens e animais. Portanto, ela parece saber que para os juruna eles não se consideram, na origem, como batatas originárias de uma primeira batata. Eles usaram uma metáfora, ao se referir ao seu herói mítico.

A palavra Sela'ã, aqui grafada na ortografia da língua, pode ser transcrita foneticamente como [ seל̧a'?ว̃ ], e morfologicamente como se-la' ã, em que têmse as glosas | se- | "1p inclusivo", | la'ã | "tubérculo, batata", com a tradução portanto "nossa batata, de nós todos". Ele também era referido, por meu principal informante de antigas narrativas, como "nosso pai", " nosso deus".

Segundo minhas pesquisas, pelos mitos juruna, Sela'ã originou-se de uma relação entre uma mulher (cuja origem não conhecemos) e Kumãhari, uma onça. Ele nunca foi literalmente uma batata. Sela'ã é explicado pelos juruna, metaforicamente, como batata por nunca morrer, por sempre se renovar, como as ramas de batata, a partir de uma original. Ao envelhecer, ele sempre trocaria de pele, assim como sua mulher, permanecendo jovens. A metáfora dos juruna enfatiza, assim, o fato de que Sela'ã diz que eles devem se perpetuar, porque 
se o povo se extinguir, ele jurou derrubar o céu (o último dos que já havia) e destruir o mundo. Assim, como Sela'ã é eterno, o povo juruna também deve ser, embora os juruna não sejam imortais, individualmente. Sela'ã os protege, como povo escolhido, e do céu, onde mora, observa a Terra, com uma grande estrela, interpretada como um telescópio, para proteger seu povo que deve se perpetuar.

Para os juruna, segundo o que me relatou Tarinu, o avô de uma pessoa não é considerado seu inã'ã (ou, na ortografia, ila'ã), uma vez que um avô não renasce, um avô é mortal, diferentemente de Sela'ã, que é imortal. Um avô, portanto, não poderia ser considerado uma batata, metaforicamente. Como ficaria a explicação de Lima, portanto? Se o uso da metáfora juruna para explicar seu sistema de parentesco é inadequado, a análise também seria? Qual o alcance de uma metáfora? Estaríamos sempre autorizados a usar a metáfora alheia para embasar nossas explicações? Qual a força da metáfora do outro?

\section{Lima (1995) usa a metáfora conceptual:}

\section{SISTEMA DE PARENTESCO É BATATEIRAL}

A partir dela, ela afirma que 'o avô tem o papel de batata matriz', expressão metafórica, que liga os domínios de parentesco e plantação. Mas quanto aos mapeamentos licenciados, ou seja, as relações, tais como 'o avô é a origem', 'o avô é imortal', 'o avô e seus descendentes possuem relacionamento concêntrico', etc, podemos pensar que sejam ilícitos, pois não são reconhecidos pelos integrantes da comunidade analisada, uma vez que a relação direta com Sela'ã não é autorizada. E isso é problema, porque os mapeamentos devem ser relevantes para as culturas que os têm, devem ser lícitos para elas. Senão, qualquer metáfora valeria como explicação.

A análise do sistema de parentesco do juruna, em linhas gerais, feita por Lima (op.cit.) é digna de mérito, mas foi realizada em época em que a população juruna era menor e com isso, as genealogias a que ela teve acesso, com certeza, eram incompletas, pois dificilmente, naquela época, uma pessoa possuiria boa parte de seus parentes vivos, ou mesmo desconheceria antepassados como tios e avós. Alie-se a isso o fato de que o nome dos falecidos não é pronunciado por seus parentes e percebe-se a dificuldade da pesquisadora para obter os dados de que precisava. Hoje, com uma população bem maior, e, portanto, com a possibilidade de obtenção de genealogias mais completas, este estudo poderia trazer outros resultados e considerações.

\section{Imagens-metáfora e o belo}

Em Sãluahã, o retorno à festa, documentário que realizei entre os juruna, lançado em 2000 e reeditado em 2010, mostro a festa de término de reclusão de duas meninas. Tal reclusão havia se dado após a menarca de ambas, que 
ficaram em um jirau, na parte de cima de suas casas, por aproximadamente um ano. Fui convidada para registrar a festa, que contou com trechos de todas as festas dos juruna, que tocaram praticamente todos os seus instrumentos musicais. Fiz uma breve análise, relacionando céu e terra, o que é discutido ao final do documentário. Em determinado momento, na narração, chamei as meninas de 'vestais', numa metáfora relacionando-as às meninas dos templos romanos, que cuidavam do fogo e serviam nas cerimônias, uma vez que, como elas, Areaki e Miuda aprendiam os costumes de seu povo, suas artes, e, ao saírem da reclusão, levavam no centro da testa um enfeite de algodão vermelho, tradicional de seu povo, que se relaciona ao sol, o grande fogo, o qual para os juruna é um homem com cocar de fogo. Tive consciência do uso metafórico que fiz, motivada por uma representação de beleza e pureza semelhante. Afinal, nosso olhar de observador, embora procure manter-se distante de nossa cultura, tentando compreender o outro pela forma com que ele se apresenta, continua sendo um olhar que vem de uma cultura específica, e que, apesar de não a usar como explicação de tudo, o que seria procurar a nós mesmos no outro, vê o belo como o belo existe para nós.

Nem todo pesquisador tem esta postura, revelando, por vezes, o bizarro no outro, o feio e o desagradável, o que se evidencia em suas metáforas. Por exemplo, podemos ler em Lévi-Strauss:

O Pão de Açúcar, o Corcovado, todos esses pontos tão enaltecidos lembram ao viajante que penetra na baía [de Guanabara] cacos perdidos nos quatro cantos de uma boca desdentada. (...) Perto do mar e por uma ilusão contrária de Nova York, aqui é a natureza que se reveste de um aspecto de canteiro de obras. (Lévi-Strauss 1999 [1955]: 75)

Este é um olhar pouco lisonjeiro para o Brasil, a quem muito o antropólogo ficou devendo. Observam-se três metáforas infelizes - "cacos perdidos", "boca desdentada" e "canteiro de obras" - entre tantas descrições de alguém de passagem. Ele não poderia ter visto a beleza, a majestade da paisagem do Rio de Janeiro?

Uma reação a isso veio de Caetano Veloso:

O pintor Paul Gauguin amou a luz na Baía de Guanabara

O compositor Cole Porter adorou as luzes na noite dela

A Baía de Guanabara

O antropólogo Claude Lévi-Strauss detestou a Baía de Guanabara:

Pareceu-lhe uma boca banguela.

E eu menos a conhecera mais a amara?

Sou cego de tanto vê-la, de tanto tê-la estrela

O que é uma coisa bela?

(Caetano Veloso - O Estrangeiro, primeira faixa do álbum de 1989) 


\section{Para concluir...}

Iniciei este texto me perguntando como poderíamos entender as metáforas de outras línguas/culturas e em que medida estenderíamos suas metáforas para nossas teorias e análises. Estas perguntas ficam sempre em aberto e requerem do pesquisador uma atitude de pesquisa constante. Ao compreendermos mais e mais a língua/cultura que estudamos é que podemos vislumbrar sentidos diferentes, intenções e imagens, que, por vezes, podem ser muito distintas do que temos em nossa própria língua/cultura. Isso pode levar tempo, pode levar a abandono de interpretações que já fizemos, depois de outras informações, de outros elementos de análise.

Na relação pesquisador - falante da língua, precisamos pensar nas metáforas que fazemos, se são adequadas, ou se 'chocam'. Afinal, um pesquisador deveria também pensar no belo, pois um espírito crítico não precisa necessariamente apresentar sempre imagens que causem dissabor, revolta. Ciência e Arte podem mesmo ter uma relação próxima, como bem mostrou o próprio Lévi-Strauss, ao utilizar a música como metáfora em sua obra, $O$ cru e o cozido, Mitológicas 1 . Se não foi a beleza que o motivou, o que teria sido?

Finalmente, para responder à pergunta-título, qual o alcance de uma metáfora?, acredito que precisamos também entender as metáforas alheias através dos seus próprios mapeamentos, e não daqueles que pensamos serem interessantes para nossas análises. Isso é possível e desejável. É preciso, para tanto, pensar a relação língua-cultura, língua-pensamento, de uma forma profunda, em que se dissolvam dicotomias no fazer teórico, como aponta Moura (2008), percebendo-se que uma metáfora é criada pela cognição, mas através da língua, que, como aponta Everett (2012), pode ser pensada como uma ferramenta cultural.

\section{Referências}

Everett, D. 2012. Language - The cultural tool. New York: Pantheon Books.

Fargetti, C.M. 2015. Kinship and some lexicographic issues. In: J. P. Silvestre; A. Villalva. Planning non-existent dictionaries. Lisboa: Universidade de Lisboa, Universidade de Aveiro.

. 2010. Sãluahã, o retorno à festa. Reedição. vídeo. Piracicaba, SP: Filó comunicações.

2007. Estudo Fonológico e Morfossintático da Língua Juruna. Muenchen, Alemanha: Lincom Europa, 320p.

1992. Análise fonológica da língua Juruna. Dissertação (Mestrado), Campinas, SP, UNICAMP.

Lakoff, G.; M. Johnson. 2002 [1980]. As metáforas da vida cotidiana. Campinas, SP: Mercado de Letras/EDUC. 
Lévi-Strauss, C. 2004 [1964]. O cru e o cozido. (Mitológicas vol. 1). São Paulo: Cosac \& Naify. Vozes. 2003 [1967]. As estruturas elementares do parentesco. 3. ed. Petrópolis, RJ: 1999 [1955]. Tristes Trópicos. São Paulo: Companhia das Letras.

Lima, T. S. 1995. A parte do Cauim - etnografia juruna. Tese (Doutorado), Rio de Janeiro, UFRJ.

Moura, H. 2012. Vamos pensar em metáforas? São Leopoldo, RS: Editora UNISINOS. . Desfazendo dicotomias em torno da metáfora. Revista de Estudos Linguísticos $16(1), 2008$. 2007. Relações paradigmáticas e sintagmáticas na interpretação de metáforas. Linguagm em (Dis)curso. LemD 7 (3):417-452, set./dez., 2007.

Oliveira, A. E. 1970. Os índios juruna do Alto Xingu. Dédalo VI, 11, 12, São Paulo: USP.

Reifschneider, F. J. B. 1987. Produção de Batata. Brasília, DF: Centro Nacional de Pesquisa de Hortaliças/EMBRAPA. (Imagem "botânica" extraída desta obra e disponível no site da ABBA, Associação Brasileira da Batata: <http://www. abbabatatabrasileira.com.br/abatata_botanica.htm $>$ )

Rodrigues, A. D. 1986. Línguas Brasileiras. Para o conhecimento das línguas indigenas. São Paulo: Loyola.

Sardinha, T. B. 2007. Metáfora. São Paulo: Parábola.

Veloso, C. 1989. Estrangeiro. LP, PolyGram do Brasil.

Viveiros de Castro, E. 2004. Perspectival Anthropology and the Method of Controlled Equivocation. Tipiti 2 (1).

. 1996. Os pronomes cosmológicos e o perspectivismo ameríndio. Mana. 2(2):115-144.

Data recebimento: $18 / 06 / 2015$

Data aceite: 15/07/2015 